\title{
Menopause-Related Symptoms and Help Seeking Behavior among Women Attended at a Tertiary Care Hospital in Bangladesh
}

\author{
Rumi Farhad Ara ${ }^{*}$, Md. Jahangir Alam², Md. Abdullah Yusuf ${ }^{3}$ \\ ${ }^{1}$ Department of Gynaecology \& Obstetrics, Kushtia Medical College, Kushtia, Bangladesh \\ ${ }^{2}$ Department of Surgery, Shaheed Suhrawardy Medical College, Dhaka, Bangladesh \\ ${ }^{3}$ Department of Microbiology, National Institute of Neurosciences \& Hospital, Dhaka, Bangladesh \\ Email: *rumidr12@gmail.com, jahagnirdr11@gmail.com, ayusuf75@yahoo.com
}

How to cite this paper: Ara, R.F., Alam, Md.J. and Yusuf, Md.A. (2018) Paper Title. Open Journal of Obstetrics and Gynecology, 8, 376-384.

https://doi.org/10.4236/ojog.2018.84042

Received: February 11, 2018

Accepted: April 16, 2018

Published: April 19, 2018

Copyright (c) 2018 by authors and Scientific Research Publishing Inc. This work is licensed under the Creative Commons Attribution International License (CC BY 4.0).

http://creativecommons.org/licenses/by/4.0/

\section{(c) (i) Open Access}

\begin{abstract}
Background: Women have experienced different menopause-related symptoms. Objective: The purpose of the present study was to see the menopause-related symptoms and help seeking behavior among the women attended at a tertiary care hospital. Methodology: This cross-sectional study was conducted in the outpatient Department of Kushtia Medical College Hospital, Kushtia, Bangladesh from October 2015 to September 2016 for a period of one (01) year. Menopausal women who were attended in the outpatient Department of Hospital were included as study population. The eligible women had at least one year of amenorrhoea. Surgical menopause or due to severe illness, extreme weight loss endocrine disorders or radio therapy were excluded. Each subject completed a questionnaire that elicited their sociodemographic information, personal and family history and current medical problems. Result: A total number of 437 women were recruited for this study. The most prevalent menopausal symptom among the participants was generalized body ache $91.30 \%$. Followed by low back pain $88.55 \%$, muscle \& joint pain $87.18 \%$, tiredness $86.04 \%$, hot flush $64.30 \%$, urinary symptoms $43.93 \%$, vaginal dryness $48.28 \%$, insomnia $73.91 \%$, irritability $23.56 \%$. Most of the participants consulted at first with village doctors $(63.15 \%)$ followed by general practitioners $20.82 \%$ due to their health problems. Some sought help from traditional healers like kobiraj 3.20\%. Conclusion: In conclusion, body ache, low back pain, muscle and joint pain and tiredness are the most commonly reported menopause-related symptoms that are mostly consulted with village doctors.
\end{abstract}

\section{Keywords}

Menopause, Symptoms, Help Seeking Behavior 


\section{Introduction}

Menopause is defined as a Physiological event in which there is at least twelve consecutive months of amenorrhoea caused by depletion of ovarian function [1]. This natural Hormone deficient state occurs at the age of 45 to 55 years [2] [3] [4]. After the age of 40 years ovaries reduce their production of sex hormones [5] [6]. This results in various somatic, vasomotor, sexual and psychological symptoms that impair the overall quality of life of women [7] [8]. The physical symptoms commonly associated with menopause include tiredness, generalized body pain, internal heat, sweating, back pain, restlessness, unhappiness, dryness of skin, shrinking of body.

Urogenital symptoms reported include vaginal dryness, itching, discomfort, voicer dyspareunia, urinary incontinence, incomplete voiding, heaviness at birth passage, prolapse of genital organs. Sexual problems like loss of libido and primary sleep disorders are noticed in this group of women [9].

Combination of factors such as loss of fertility, fear of aging and physical attractiveness, reduced activity and changes in family roles may lead to depression [10]. The psychological symptoms include forgetfulness and irritability, insomnia, headache and anxiety. All these somatic and psychological changes affect the quality of life. But the two important health factors, cardiovascular diseases and osteoporosis are major cause of morbidity in postmenopausal women [11].

Symptoms vary extensively and differ from one study to other. For some symptoms are so severe that it disrupts their daily activities but for others they are mild and the transition is acceptable [12]. However the interpretation of menopausal symptoms is not as other hormone deficient condition and only hormone replacement fails to reverse the manifestations. Beside women's social educational, cultural background and the aging process all have a significant influence. This present study was undertaken to see the menopause-related symptoms and help seeking behavior among the women attended at a tertiary care hospital.

\section{Methodology}

This was a descriptive type of cross-sectional study. This study was conducted in the outpatient Department of Kushtia Medical College Hospital, Kushtia, Bangladesh. The duration of study was one year from October 2015 to September 2016 for a period of one (01) year. Kushtia Medical College Hospital, Kushtia was a tertiary care teaching public hospital. This hospital was the only hospital in this region west side of the Bangladesh. This hospital represented the only Government hospital in that area of Bangladesh. There was a he number of patients came here to get treatment. Menopausal women who were attended in the outpatient Department of Hospital were included as study population. The eligible women had at least one year of amenorrhoea. Surgical menopause or due to severe illness, extreme weight loss endocrine disorders or radio therapy were excluded. Data was collected from all eligible respondents by face to face interview 
using structured questionnaire which contains several variables like sociodemographic information, personal and family history and current medical problems. Each subject completed a questionnaire. Participants' chief complaints included at least one moderate to severe or two mild symptoms from the menopause rating scale (MRS) [13]. The MRS is a self rating scale for the assessment of menopausal complaints. It has been proved to have good applicability and reliability [14]. It consists of 11 symptom items. Each symptom item is rated on a 5-point scale, none, mild, moderate, marked, severe and is scored from 0 (none) to 4 points (severe symptoms). The total score of MRS was ranged between 0 (asymptomatic) and 44 (highest degree of complaints). The assessing item focused mainly on somatic like hot flushes, heart discomfort, sleep problem and muscle and joint problems; psychological like depression, irritability, anxiety, physical and mental exhaustion and urogenital like sexual problems, bladder problems, dryness of vagina. To get information on their health seeking behavior a structured questionnaire was used containing straight dichotomous and close ended questions. The questions asked about the onset when menopausal symptoms were first recognized, the time of contact when the participant had first professional medical consultation and sources of treatment prior to hospital visit. Statistical analysis was performed using the statistical package for the social sciences for windows version 16.0. Prior to the commencement of this study, the research protocol was approved by the Institutional Review Board of Kushtia Medical College Hospital, Kushtia. The aims and objectives of the study were explained to the patients in easily understandable local language and then informed consent was taken from each patient. It was assured that all informed and records were kept confidential and the procedure was helpful for both the doctor and the patients in making rational approach of the case management.

\section{Results}

In this study a total of 437 women were recruited with ages ranging from 35 to 75 years (Table 1 ).

The majority of women were within 45 to 54 years age group (72.21\%) (Table 2).

Majority of the subjects in the study were married (98.16\%) and not employed outside the home (76.42\%) (Table 3 ).

The level of educational attainment was generally low among the subjects, with majority having no formal education (52.86\%) (Table 4).

Most of them were economically dependent on their husband (50.57\%), (32.95\%) on their children, (2.05\%) on their relatives, only (14.41\%) were self-dependent (Table 5 and Table 6).

By coupling status majority were $(67.96 \%)$ found living with their husband, (29.29\%) were widows. (1.83\%) were divorce and $(0.91 \%)$ were living separately (Table 7). 
Table 1. Distribution of participants by age group.

\begin{tabular}{ccc}
\hline Age Group & Frequency & Percentage \\
\hline 35 to 44 Years & 97 & 22.2 \\
45 to 54 Years & 141 & 32.3 \\
55 to 64 Years & 123 & 28.1 \\
65 to 74 Years & 73 & 16.7 \\
More Than 75 Years & 03 & 0.7 \\
Total & 437 & 100.0 \\
\hline
\end{tabular}

Table 2. Age of menopause among participants.

\begin{tabular}{ccc}
\hline Age Years & Frequency & Percentage \\
\hline Less Than 44 Years & 117 & 26.8 \\
45 to 54 Years & 311 & 71.2 \\
More Than 55 Years & 9 & 2.0 \\
Total & 437 & 100.0 \\
\hline
\end{tabular}

Table 3. Distribution of participants by education.

\begin{tabular}{ccc}
\hline Education Level & Frequency & Percentage \\
\hline No Formal education & 231 & 52.9 \\
Primary & 113 & 25.8 \\
Secondary & 79 & 18.1 \\
Higher Secondary & 11 & 2.5 \\
Tertiary & 3 & 0.7 \\
Total & 437 & 100.0 \\
\hline
\end{tabular}

Table 4. Distribution of participants by marital status.

\begin{tabular}{ccc}
\hline Marital Status & Frequency & Percentage \\
\hline Living with Husband & 297 & 68.0 \\
Window & 128 & 29.3 \\
Divorce & 8 & 1.8 \\
Separated & 4 & 0.9 \\
Total & 437 & 100.0 \\
\hline
\end{tabular}

Table 5. Distribution of participants by economical dependency.

\begin{tabular}{ccc}
\hline Economical Dependency & Frequency & Percentage \\
\hline Self & 63 & 14.4 \\
Husband & 221 & 50.6 \\
Children & 144 & 32.0 \\
Others & 9 & 2.0 \\
Total & 437 & 100.0 \\
\hline
\end{tabular}


Table 6. Distribution of participants by monthly family income.

\begin{tabular}{ccc}
\hline Monthly Family Income & Frequency & Percentage \\
\hline Less Than 5 thousand Taka & 61 & 13.9 \\
5 to 10 thousand Taka & 228 & 52.17 \\
10 to 15 thousand Taka & 123 & 28.14 \\
More Than 15 Taka & 25 & 05.72 \\
Total & 437 & 100.0 \\
\hline
\end{tabular}

Table 7. Distribution of participants by occupation.

\begin{tabular}{ccc}
\hline Occupation & Frequency & Percentage \\
\hline House Wife & 231 & 52.86 \\
Farming & 103 & 23.56 \\
Trading & 64 & 14.64 \\
Official Job & 03 & 0.68 \\
House keeping & 23 & 5.26 \\
Others & 13 & 2.97 \\
Total & 437 & 100.0 \\
\hline
\end{tabular}

The most prevalent menopausal symptom among the participants was generalized body ache $91.30 \%$. Followed by low back pain $88.55 \%$, Muscle \& joint pain $87.18 \%$, tiredness $86.04 \%$, hot flush $64.30 \%$, urinary symptoms $43.93 \%$, vaginal dryness $48.28 \%$, insomnia $73.91 \%$, irritability $23.56 \%$ (Table 8 ).

Most of the participants consulted at first with village doctors $63.15 \%$ followed by general practitioners $20.82 \%$ due to their health problems. Some sought help from traditional healers like kobiraj 3.20\% (Table 9).

\section{Discussion}

This study was an attempt to determine health problems in menopausal women which healthcare professional they visit first for treatment and their awareness about menopausal transition. The study found that $71.17 \%$ of women had menopause at the age of 45 - 54 year. This result is consistent with the report of a WHO scientific group research on the menopause where the age was mentioned 47 - 48 years for developing countries [14]. Similar result was found in India where mean menopausal age was 47.35 years in urban Indian women [15] and 49.56 years in rural Indian women [16]. Similar result also found in a study done among Nepalese women by Gyawali et al. [17] where mean menopausal age was found $46.3 \pm 4.78$ years.

The study found a high prevalence of somatic problems related to menopause Generalized body pain is the most prevalent symptom (91.3\%) followed by low-back pain (88.5\%) muscle and joint pain (87.2\%) Psychological symptoms are least reported $(23.6 \%)$. The findings in this study are similar to the findings by Pan et al. [18] among post-menopausal women in Tiwan. 
Table 8. Distribution of participants by problem related to menopause (Multiple response).

\begin{tabular}{ccc}
\hline Problem related to Menopause & Frequency & Percentage \\
\hline Hot flushes & 281 & 64.3 \\
Generalized body pain & 399 & 31.30 \\
Low back pain & 387 & 88.55 \\
Muscle of joint pain & 381 & 87.18 \\
Tiredness & 376 & 86.04 \\
Insomnia & 323 & 73.91 \\
Irritability Anxiety & 103 & 23.56 \\
Vaginal Dryness & 211 & 48.28 \\
Urinary Symptoms & 192 & 43.93 \\
Dyspareunia & 91 & 20.82 \\
Something coming down through vagina & 33 & 7.55 \\
\hline
\end{tabular}

Table 9. Help seeking practices of women with menopausal symptoms.

\begin{tabular}{ccc}
\hline Seeking Consultation & Frequency & Percentage \\
\hline Village Doctors & 158 & 36.1 \\
Kobiraj & 14 & 03.2 \\
Pharmacy & 68 & 15.6 \\
General Practitioner & 91 & 20.8 \\
Gynecologist & 72 & 16.5 \\
Cardiologist & 21 & 4.8 \\
Orthopaedician & 13 & 3.0 \\
\hline
\end{tabular}

A high prevalence of general body pain in $87.5 \%$, waist pain in $86.8 \%$ and joint pain in $85.5 \%$ of study population was reported by Paul et al. [19] of Nigeria. A similar result was also reported. In their study muscle pain (87.53\%) joint pain $(85.45 \%)$, tiredness $(80.26 \%)$ were among the most prevalent menopausal symptoms the subjects presented with. However the loss of libido remains at the top of the list. This symptom was reported by $92.47 \%$ subjects [20]. The high prevalence of loss of libido in this study could have emanated from the fact that most of the subjects in this study were windows and divorces whose emotional status could have contributed to their experience. Besides many cultures hold on different beliefs about menstruation [21].

Variation observed in the menopausal symptoms in different studies. Among Jordanian women vasomotor symptoms were reported to have the highest scores as manifested by hot flushes and night sweating [22]. About $75.0 \%$ to $85.0 \%$ of American women are estimated to experience hot flushes during menopause [23]. Contrary to this picture a low prevalence of hot flushes (12\% to $20 \%)$ in Asian women was reported by Pen et al. [18]. 
A similar report is found in a study among Mayan women in Mexico [23]. These contradictory results may be explained by cultural, social, economic, psychic or physiological differences in patients in the different study locations [24]. Studies investigating factors influencing the prevalence, type and severity of menopausal symptoms have explored that, a lower socioeconomic status, unemployment and lower educational level are associated with increased prevalence and severity of menopausal symptoms findings in this study is consistent with prior studies [25].

In this study it is found that most of the women seek health support from village doctors. They are close to the people and their services seem to be cheap [26]. This finding is a source of concern as they are often untrained and help to perpetrate the vicious circle of counterfeit and death [27]. The Unfriendly attitude of health workers, perceived high cost of hospital services lack of drugs and basic laboratory services, non availability of a regular physician on seat at the facility and delays in services in hospital could have accounted for this [28]. They frequently visited general practitioners. They consulted gynecologists mainly due to urogenital symptoms [26] [27] [28]. Women having palpitation, restlessness, vertigo, hot flushes visited cardiologists [25] [27]. In case of musculoskeletal symptoms they frequently consulted orthopaedicians. Also a number of women sought the help of pharmacists and traditional healers like Kobiraj.

Health care providers need to treat the person from a lifestyle management perspective. Attention only to a discrete problem will not be helpful. It is important to increase the mass peoples understanding of menopause and to improve cooperation between the various healthcare providers of different specialties [27]. The health ministry and health directorate of Bangladesh has taken different population based health intervention programs at different heath care facilities of our country. In this perspective establishment of a "health care corner for perimenopausal women" would be a good step to address this health issue. So the women can perceive menopause as an opportunity to concentrate on new activities and bring out the best in her [28].

There are some limitations of this study. This was a single centred hospital based study. Therefore there was a selection bias present in this study. Again randomization was not done.

\section{Conclusion}

Most of the respondents have inadequate knowledge about menopause and its effects on physical and mental health. They are ignorant about the need of proper health care at this transitional period of life. They also have poor knowledge about care seeking. So in spite of available health facilities in the communities the utilization of services is not optimum. So to improve the quality of life more attention is to be paid on health education about menopausal changes and encouraging the women to seek health care at right time from a right person. Large scale study should be carried out to see the status of the Bangladesh. 


\section{References}

[1] Nisar, N. and Sohoo, N.A. (2010) Severity of Menopausal Symptoms and the Quality of Life at Different Status of Menopause: A Community Based Survey from Rural Sindh, Pakistan. International Journal of Collaborative Research on Internal Medicine \& Public health (IJCRIMPH), 2, 118-130.

[2] Sallam, H., Galal, A.F. and Rashed, A. (2006) Menopause in Egypt: Past and Present Perspectives. Climacteric, 9, 421-429. https://doi.org/10.1080/13697130601030170

[3] Amore, M., Di Douanto, P., Berti, A., Palareti, A., Chirico, C., Papalini, A. and Zucchini, S. (2005) Sexual and Psychological Symptoms in the Climacteric Years, Acta obstet Gynecol Scand, 80, 1071-1077.

[4] Anttalainen, U., Saaresrsnta, T., Aittokallio, J., Kalleiren, N., Vahlberg, T., Virtanen, I. and Polo, O. (2006) Impact of Menopause on the Manifestation and Severity of Sleep Disordered Breathing. Acta Manifestation Gynecol Cand., 85, 1381-1388.

[5] Melby, M.K. (2005) Factor Analysis of Climacteric Symptoms in Japan. Maturitas, 52, 205-222.

[6] Vanwesenbeeck, I., Venrix, P. and Van de Wiel, H. (2001) Menopausal Symptoms: Associations with Nemopausal Symptoms and Psychological Factors. Journal of Psychosomatic Obstetrics and Gynaecology, 22, 149-158.

[7] Deeks, A.A. and McCabe, M.P. (2004) Wellbeing and Menopause: An Investigation of Purpose in Life, Self Acceptance and Social Role in Premenopausal, Perimenopausal and Postmenopausal Women. Quality of Life Research, 13, 389-398. https://doi.org/10.1023/B:QURE.0000018506.33706.05

[8] Dennerstein, L., Dudly, E.C., Hopper, J.L., Guthric, J.R. and Burger, H.G. (2000) A Prospective Population Based Study of Menopausal Symptoms. Obstetrics \& Gynecology, 96, 351-358.

[9] Okonofua, F.E., Lawal, A. and Bamgbose, J.K. (1990) Features of Menopause and Menopausal Age in Nigerian women. International Journal of Gynecology \& $\mathrm{Ob}$ stetrics, 31, 341-345. https://doi.org/10.1016/0020-7292(90)90912-5

[10] Cheung, A.M., Chaudry, R., Kapral, M., Jackevicus, C. and Robinson, G. (2004) Perimenopausal and Postmenopausal Health. BMC Women's Health, 4, S23.

[11] Grodstein, F., Mauson, J.E. and Stampfer, M.J. (2001) Postmenopausal Hormone Use and Secondary Prevention of Coronary Events in the Nurses' Health Study: A Prospective, Observational Study. Annals of Internal Medicine, 135, 1-8. https://doi.org/10.7326/0003-4819-135-1-200107030-00003

[12] Schneider, H.P., Heineman, L.A., Rosemeirer, H.P., Potthoff, P. and Befre, H.M. (2000) The Menopause Rating Scale (MRS): Reliability of Scores of Menopausal Complaints. Climactric, 3, 59-64.

[13] Hsiao, M.-C., Chiang, P.-H., Liu, C.-Y. and Lin, Y.-H. (2009) Help-Seeking Behavior in Taiwanese Women with Manupause-Related Mood Symptoms. Chang Gung Medical Journal, 32, 313-319.

[14] Aryal, T.R. and Yadava, K. (2005) Age at Menopause among Nepalese Women. International Journal of Health Sciences Research.

[15] Kaulagekar, A. (2011) Age of Menopause and Menopausal Symptoms among Urban Women in Pune Maharashtra. The Journal of Obstetrics and Gynecology of India, $61,323$.

[16] World Bank (2001) Understanding the Access, Demand and Utilization of Health Services by Rural Women in Nepal and Their Constraints. World Bank, Washington DC, Report No: 30145. 
[17] Gyawali, S.N., Shubedi, N. and Yasmin, S. (2016) Pandey Health Care Seeking Practice for Menopausal Problems among Woman in Syangia District, Nepal. International Journal of Health Sciences \& Research, 6, Issue 8.

[18] Pan, H.A., Wa, M.H., Hsu, C.C., Yao, B. and Huang, K.E. (2002) The Perception of Menopause among Women in Taiwan. Maturitas, 4, 264-274.

[19] Paul, O.D., Funsho, J. and Geraldine, N. (2013) Frequency of Symptoms and Health Seeking Behavior of Menopausal Women in an Out-Patient Clinic in Port Harcourt, Nigeria. Global Journal of Health Science, 5, 39-47.

[20] Kumar, A. and Srivastava, K. (2011) Cultural and Social Practices Regarding Menstruation among Adolescent Girls. Social Work in Public Health, 26, 595-604. https://doi.org/10.1080/19371918.2010.525144

[21] Gharaibeh, M., Al-obeisat, S. and Hittab, J. (2010) Severity of Menopausal Symptoms of Jordanian Women. Climacteric, 13, 385-394. https://doi.org/10.3109/13697130903050009

[22] Green, R. and Santoro, N. (2009) Menopausal Symptoms and Ethnicity: The Study of Women Health across the Nation. Women's Health, 5, 127-133.

[23] Beyene, Y. and Martin, M. (2001) Menopausal Experiences and Bone Density of Mayan Women in Yucatan Mexico. American Journal of Human Biology, 13, 505-511.

[24] Punyahotra, S. and Dennerstein, L. (1997) Menopausal Experiences of Thai Women, Part 2: The Cultural Context. Maturitas, 26, 9-14. https://doi.org/10.1016/S0378-5122(96)01078-X

[25] Polit, D.F. and LaRoCCo, S.A. (1980) Social and Psychological Correlates of Menopausal Symptoms. Psychosomatic Medicine, 42, 335-345. https://doi.org/10.1097/00006842-198005000-00004

[26] Ige, K.O. and Nwachukwu, C. (2009) Health Care Seeking Behaviour Market Traders in Ibarapa Central Local Government, Nigeria. The International Journal of Health, 9.

[27] Sule, S.S. and Ijadunola, K.T. (2008) A Study on the Utilization of Primary Health Care Facilities in a Rural Community. Nigerian Journal of Medicine, 17, 98-106.

[28] Colombel, A. and Charbonel, B. (1997) Weight Gain and Cardiovascular Risk Factor and the Post Menopausal Women. Human Reproduction, 12, 134-145. 